\title{
What Can We Learn from the ELPSA, SA, and PSA Frameworks? The Experience of SEAQiM
}

\author{
Fadjar Shadiq \\ Yogyakarta, Indonesia \\ fadjar_p3g@yahoo.com
}

\begin{abstract}
One of education problems in Indonesia according to Dr. Anies Baswedan, the former Minister of Education and Culture of the Republic of Indonesia, was: "How to help Indonesian students to be independent learners and have good characters?" This question then raises an issue: "What kinds of knowledge, skills, and attitudes are needed by our students to survive in the $21^{\text {st }}$ Century and beyond?" Earlier the author stated (Shadiq, 2016a) that to change and improve the quality of the teaching and learning process from a 'typical' or 'traditional' mathematics classroom to a more innovative one was not easy. A further issue was: "How to change real teaching practice?" Mathematics teachers need to experience ways that they will be expected to implement in their teaching. Isoda (2011) proposed a Problem Solving Approach (PSA) which consists of four steps: (1) problem posing, (2) independent solving, (3) comparison and discussion, and (4) summary and integration. In Indonesia, we can learn from Scientific Approach (SA) which covers five steps: (1) observing, (2) questioning, (3) collecting data or experimenting, (4) reasoning, and (5) communicating. In addition, Lowrie and Patahuddin (2015) proposed Experiences, Language, Pictures, Symbols, Application (ELPSA) as a lesson design framework for mathematics teaching and learning process. A problem is examined based on these three frameworks where at least 11 alternatives can be identified to solve it. The paper ends with some recommendations on how to improve Indonesian mathematics teaching.
\end{abstract}

Keywords: lesson frameworks, ELPSA, SA, PSA, independent learners

\section{Introduction}

One of education problems in Indonesia according to the former Minister of Education and Culture (MoEC), Dr. Anies Baswedan, was: "How to help Indonesian students to be independent learners and have good characters" (Kemendikbud, 2014). This question raises an important issue: "What kinds of knowledge, skills, and attitudes are needed by our students to be independent learners and have good characters so that they can survive in the $21^{\text {st }}$ Century and beyond?" Proposing to answer the issue, Shadiq stated that our students should: (1) learn mathematics meaningfully, (2) learn mathematics joyfully, (3) emphasize thinking, and (4) be independent learners (Shadiq, 2016b). This would require teachers to change and improve the quality of the teaching and learning process from a 'typical' or 'traditional' mathematics classroom to a more innovative one which is not easy (Shadiq, 2016a). Therefore another issue that arises is: "How to change real teaching practice?" It is clear that mathematics teachers need to experience the ways that they will be expected to teach. 


\section{How to Help Learner to Be Independent?}

To begin answering this question, the author examines what models Asian neighbors are using to guide their teachers. In Japan, Isoda and Katagiri (2012) stated that the general aim of education in Japan is:

... to develop qualifications and competencies in each individual school child, including the ability to find issues by oneself, to learn by oneself, to think by oneself, to make decisions independently and to act. So that each child or student can solve problems more skilfully, regardless of how society might change in the future.

To ensure that the teaching and learning of mathematics in Japan focuses on problem solving, Isoda and Katagiri (2012) proposed Problem Solving Approach (PSA) which consists of four steps: (1) problem posing, (2) independent solving, (3) comparison and discussion, and (4) summary and integration.

In anticipating the change in the future, is it possible to learn from the Japanese so that Indonesian mathematics teachers should encourage the Indonesian students to find issues, learn, think, and make decisions by themselves. In Indonesia (Shadiq, 2015), Scientific Approach (SA) has been proposed by the MoEC of the Republic of Indonesia and it consists of five steps: (1) observing, (2) questioning, (3) collecting data or experimenting, (4) reasoning and (5) communicating.

It is interesting to compare PSA and SA. The PSA, especially the first step, can support Indonesian SA. The comparison of PSA and SA can be seen in following table (Shadiq, 2015).

Table 1.

Comparison Steps of Japanese PSA and Indonesian SA

\begin{tabular}{|l|l|l|l|}
\hline Step No & Japanese PSA & Step No & Indonesian SA \\
\hline 1 & Problem posing & & \\
\hline \multirow{2}{*}{2} & \multirow{2}{*}{$\begin{array}{l}\text { Estimating the ways of solutions (planning and } \\
\text { predicting the solution) }\end{array}$} & 1 & Observing \\
\cline { 3 - 4 } & & 3 & Questioning \\
\cline { 3 - 4 } 3 & Independent solving & 4 & Collecting data or experimenting \\
\hline 4 & Comparison and discussion & 5 & Communicating \\
\hline 5 & Summary and integration & & \\
\hline
\end{tabular}

Based on the table above, it can be concluded that the teaching and learning process should be started with contextual problem which is in line with the first step of PSA to ensure that the SA can be observed during the teaching and learning of mathematics.

Similar with Japan, the focus of the Singaporean mathematics education is also on problem solving as shown in Figure 1. 


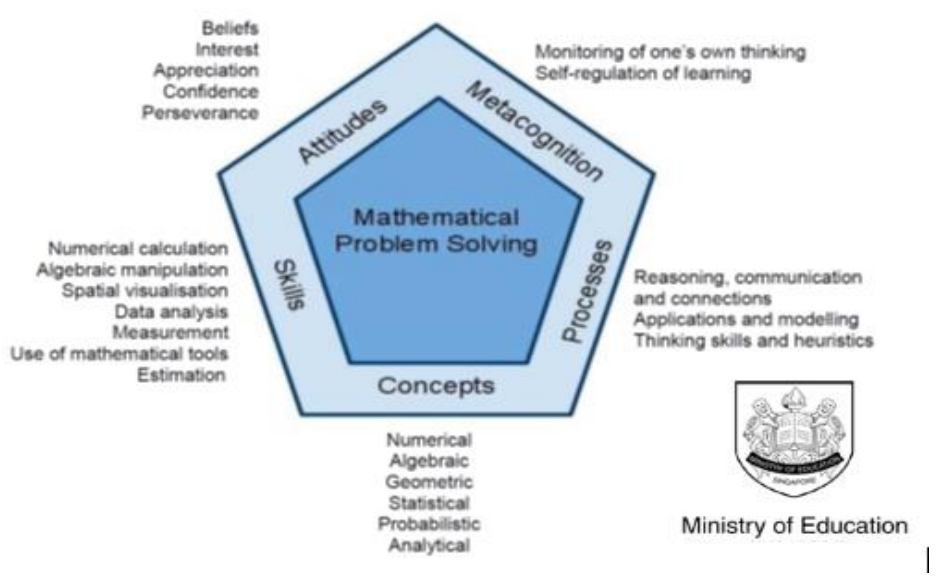

Figure 1. The focus of the Singaporean mathematics education

In Malaysia, SEAMEO RECSAM (2015) proposed Southeast Asia Basic Education Standard (SEA-BES) Common Core Regional Learning Standards in Mathematics Framework for the $21^{\text {st }}$ Century' which consist of the following components.

- Content/Strands, such as: numbers and operations, quantity and measurement, shapes, figures and solids, pattern and data representations, extension of number and operations, measurement and relations, plane figures and space solids, data representations and graphs, numbers and algebra, space and geometry, relationship and functions, and statistics and probability.

- Mathematical Processes, such as: mathematical thinking and mathematical activities.

- Values, Attitudes, and Habits for Human Character, such as: mathematical values, mathematical attitude, and habits of mind for citizen to live.

Mathematics could be seen as the language that describes patterns (De Lange, 2004, p. 8; NCTM, 2000). Thus, during the teaching and learning of mathematics in the classroom students can learn to think, solve problem, reason, and communicate. The Marquis de Condorcet (as cited in Fitzgerald \& James, 2007, p. ix) stated: "Mathematics ... is the best training for our abilities, as it develops both the power and the precision of our thinking." In addition, the National Research Council (NRC) of USA reminds us 28 years ago that:

Communication has created a world economy in which working smarter is more important than merely working harder. ... We need workers who can absorb new ideas, to adapt to change, to cope with ambiguity, to perceive patterns, and to solve unconventional problems (NRC, 1989, p. 1).

Hence, the importance and relevancy of mathematics enhance the ability of our students thinking. 


\section{What Can We Learn from SEAQiM}

The Southeast Asian Ministers of Education Organization (SEAMEO) Regional Centre for the Quality Improvement of Teachers and Education Personnel (QITEP) in Mathematics hereinafter is referred to as the SEAQiM is an organization which runs under the flag of SEAMEO and the government of Indonesia. SEAMEO itself is a regional intergovernmental organization established in 1965 among the governments of Southeast Asia countries to promote regional cooperation in education, science and culture in the region. SEAQiM was established in 2009 with the purpose to develop the capacity of mathematics teachers and education personnel across the Southeast Asian region. SEAQiM is located in Yogyakarta, a city which is famous for Javanese fine art, culture, and education.

SEAQiM has actively participated in the APEC-Tsukuba conference on Lesson Study (LS) since 2010. As a result, the Japanese PSA for students and the Japanese LS approach for mathematics teachers were usually implemented in SEAQiM courses to enhance the competence of mathematics teachers in the region. Since 2012, SEAQiM has conducted studies related to Disaster Risk Reduction (DRR) (Shadiq, 2015). The study was firstly related to an earthquake and tsunami, in 2013, 2014, and 2015, it focused on floods, volcanic eruptions, and landslides respectively. Every year, SEAQiM conducts a workshop to develop a proposal and the instruments for the study which are attended by mathematics teachers and specialists from SEAQiM.

In order to initiate change in the way mathematics is taught and learnt in Indonesian schools, four important questions as a basis for consideration are proposed, they are: (1) how to help our students to learn mathematics meaningfully, (2) how to help our students to learn mathematics joyfully, (3) how to help learners to learn to think, and (4) how to help them to be independent (Shadiq, 2016b). The fact is, many mathematics teachers focus on skills and offer mostly procedural practice. This problem can be found in Indonesia and some other SEAMEO member countries. The teachers still use the paradigm of transferring knowledge from teachers to students and it is sometimes given the title of 'transmission teaching'. In 2010 a research finding indicated most teachers of mathematics in their schools use or implement traditional ways of teaching (Shadiq, 2010, pp. 56-57).

There are other types of mathematics programs that lean more toward exploration of mathematical concepts and the building of conceptual knowledge through investigation. Here the teacher focuses up on the students' learning and towards the posing and solving problems (Askew, 2013; White, 2014). However, to change and to improve the quality of the teaching and learning process from a typical mathematics classroom to a new one that is more innovative is not easy. 
Why is it so hard to change the way teachers teach? Goos, Stillman, and Vale (2007, p. 4) stated: "Whether we are aware of it or not, all of us have our own beliefs about what mathematics is and why it is important." Furthermore, they quoted Barkatsas and Malone (2005, p. 71, as cited in Goos, Stillman, \& Vale, 2007):

\section{Mathematics teachers' beliefs have an impact on their classroom practice, on the ways they perceive teaching, learning, and assessment, and on the ways they perceive students' potential, abilities, dispositions, and capabilities.}

In order to assist teachers to change their beliefs, mathematics teachers need to experience the ways in which they will be expected to teach. Experience of successful teaching and learning will help belief change, but what experiences should the teachers receive? Lowrie and Patahuddin (2015) proposed ELPSA as a lesson design framework for the mathematics teaching and learning process. This framework could assist the teachers in their lesson planning.

\section{What Can We Learn from ELPSA}

First, like all the frameworks we start with a problem from Lowrie and Patahuddin (2015).

Problem : Can you find the number of matchsticks used for Fig 30?

Extended Problem : In how many ways can you find the number of matchsticks used for Fig 30?

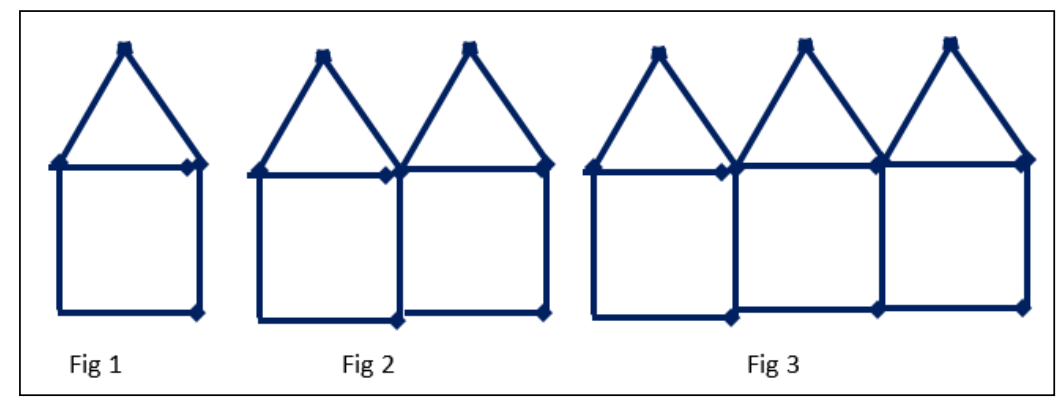

Figure 2. Problem: Can you find the number of matchsticks used for Fig 30?

There are at least 11 alternatives to solve the problem as follows.

\section{Alternative 1}

The first alternative is compiling a table by building and counting.

Table 2.

Number of Matches Used to Build Each Figure

\begin{tabular}{|l|l|l|l|l|l|l|l|l|l|}
\hline Fig ... & 1 & 2 & 3 & 4 & 5 & 6 & 7 & $\ldots$ & 30 \\
\hline Number of Matchsticks & 6 & 11 & 16 & 21 & 26 & 31 & 36 & $\ldots$ & $?$ \\
\hline
\end{tabular}

From the table the students can find that for Fig 30 the number of matchsticks needed is 151 . 


\section{Alternative 2}

By looking at the pattern on Table 3, students can study the relationship of 'Number of Fig ...' and 'Number of Matchsticks' needed, especially for the even numbered figures. Students can observe that the answer is given by a two digit number for the 'Number of Matchsticks'. The unit position of the two digit answer is always 1, while the tens digit of 'Number of Matchsticks' is always a half of the 'Number of Figure'. They can observe that for 'Number of Fig ...' for the even numbers, for example, Fig 10, then the tens digit is 5 and the number of matches is 51 , as the tens digit is 5 which is a half of 10 , while the unit digit is 1 . According to the table provided, students can decide that on Fig 30 the number of matchsticks is 151 .

Table 3 .

Number of Matches Used to Build Each Even Numbered Figure

\begin{tabular}{|l|l|l|l|l|l|l|l|}
\hline Number of Fig ... & 2 & 4 & 6 & 8 & 10 & $\ldots$ & 30 \\
\hline Number of Matchsticks & 11 & 21 & 31 & 41 & $?$ & $\ldots$ & $?$ \\
\hline
\end{tabular}

\section{Alternative 3}

The ELPS and the diagram below facilitate students to look for a pattern and to draw diagram suitable for the condition that the number of matchsticks on the first house is 6 , while the number of matchsticks on each of the next house is 5 . Using symbols they can observe that: $\mathrm{F} 1 \rightarrow 6, \mathrm{~F} 2 \rightarrow 6+5, \mathrm{~F} 3 \rightarrow 6+2 \times 5, \mathrm{~F} 4 \rightarrow 6+3 \times 5 \ldots$ So, on Fig 10 , the number of matchsticks is $6+9 \times 5=51$, while on Fig 30 the number of matchsticks is $6+29 \times 5=151$.

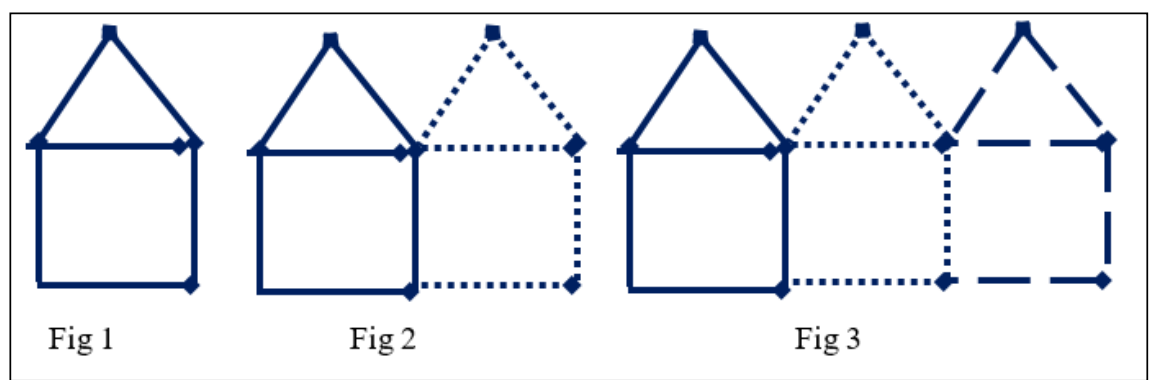

Figure 3. Alternative 3 in finding the number of matchstick on Fig 30

\section{Alternative 4}

Students can be facilitated to discover by themselves that the number of matchstick on Fig 1 is $1+5$, Fig 2 is $1+2 \times 5$, Fig 3 is $1+3 \times 5$, and so on. In other symbol, students can learn that: $\mathrm{F} 1 \rightarrow 1+5, \mathrm{~F} 2 \rightarrow 1+2 \times 5, \mathrm{~F} 3 \rightarrow 1+3 \times 5, \mathrm{~F} 4 \rightarrow 1+4 \times 5 \ldots$ Therefore, the number of matchsticks for Fig 10 is $1+10 \times 5=51$, while on Fig 30 the number of matchsticks is $1+30 \times 5=151$. 


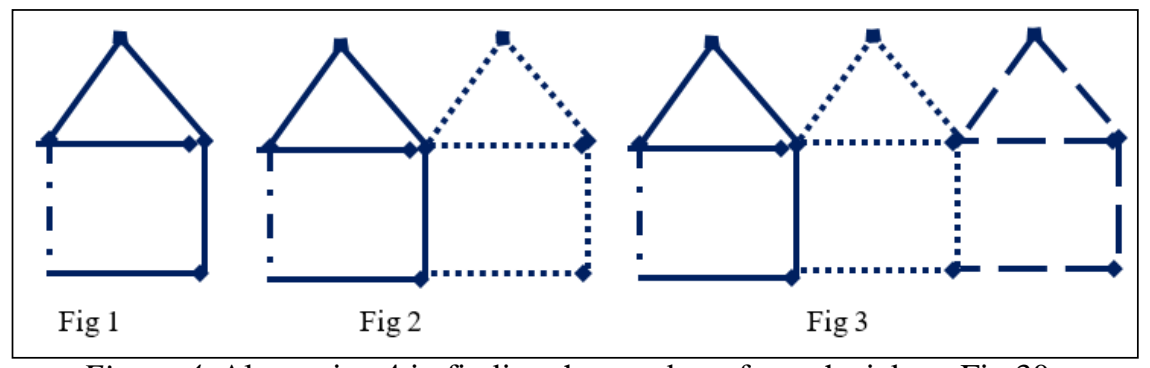

Figure 4. Alternative 4 in finding the number of matchstick on Fig 30

\section{Alternative 5}

By using ELPS and the diagram below, students can discover that the number of matchstick on each figure consist of three parts: 1 matchstick on the most left-hand side of each figure, 2 matchsticks on each roof of the house of each figure, and 3 matchsticks on the ceiling, righthand side and ground floor on the house of each figure.

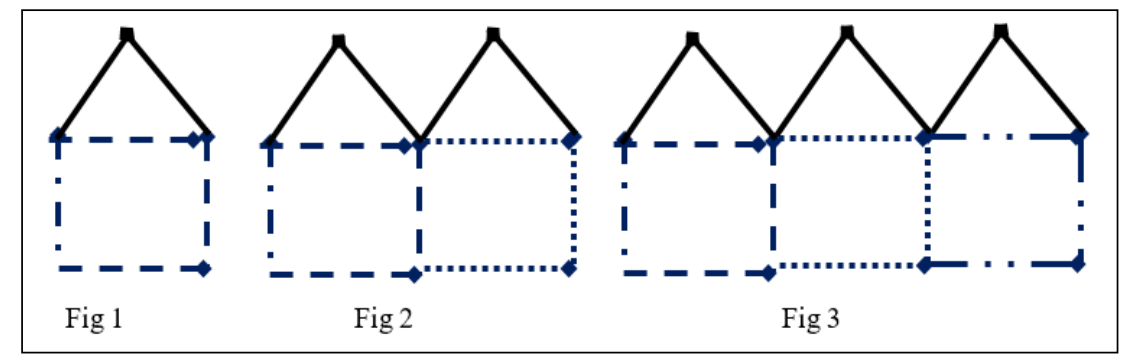

Figure 5. Alternative 5 in finding the number of matchstick on Fig 30

In other symbols, students can learn that: $\mathrm{F} 1 \rightarrow 1+2+3, \mathrm{~F} 2 \rightarrow 1+2 \times 2+2 \times 3, \mathrm{~F} 3 \rightarrow 1+3 \times 2+3 \times 3 \ldots$ So, on Fig 10 the number of matchsticks is $1+10 \times 2+10 \times 3=51$, while on Fig 30 the number of matchsticks is $1+30 \times 2+30 \times 3=151$.

\section{Alternative 6}

Alternative 6 shows that the number of matchstick on each figure consist of three parts: 1 matchstick on the most left-hand side of each figure, 3 matchsticks on roof and the ceiling on the house of each ach figure, and 2 matchsticks on the right-hand side and ground floor on the house of each figure.

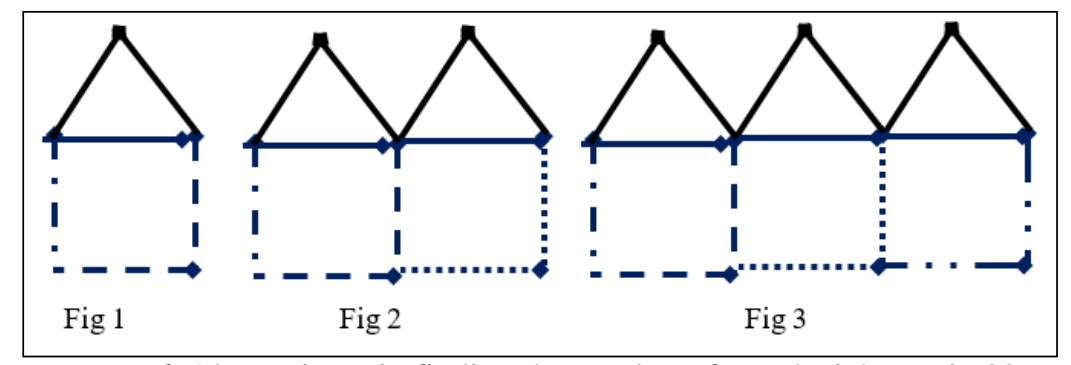

Figure 6. Alternative 6 in finding the number of matchstick on Fig 30 
Similarly, they can learn that: $\mathrm{F} 1 \rightarrow 1+2+3, \mathrm{~F} 2 \rightarrow 1+2 \times 2+2 \times 3, \mathrm{~F} 3 \rightarrow 1+3 \times 2+3 \times 3 \ldots$ Therefore, on Fig 10 the number of matchsticks is $1+10 \times 2+10 \times 3=51$ and on Fig 30 the number of matchsticks is $1+30 \times 2+30 \times 3=151$.

\section{Alternative 7}

Looking at Figure 7 and the ELPS facilitates students to discover that there are 4 matchsticks on the first house, 3 matchsticks on the next house of each figure, and 2 matchsticks on each house of each figure. On the other way: $\mathrm{F} 1 \rightarrow 4+2, \mathrm{~F} 2 \rightarrow 4+3+2 \times 2, \mathrm{~F} 3 \rightarrow 4+2 \times 3+3 \times 2 \ldots$ As the results, students need $4+9 \times 3+10 \times 2=51$ matchsticks to make Fig 10 and $4+29 \times 3+30 \times 2=151$ matchsticks to build Fig 30 .

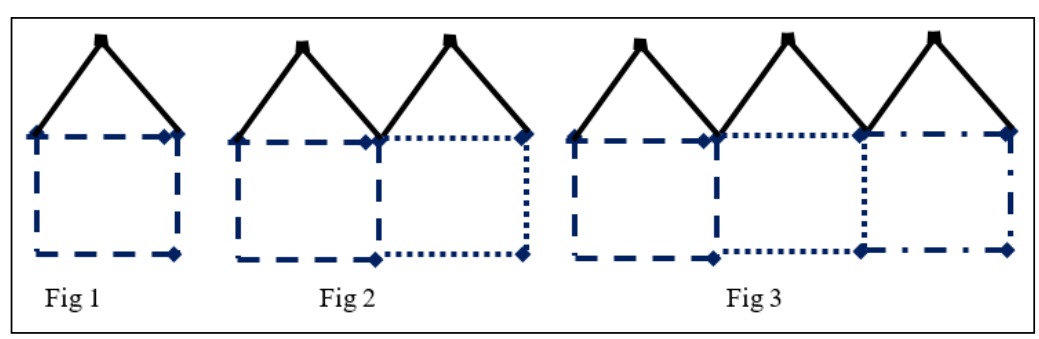

Figure 7. Alternative 7 in finding the number of matchstick on Fig 30

\section{Alternative 8}

In Alternative 8, students can find out that the number of matchstick on each house consists of 6 , however the middle walls of the house has been counted twice, so the students have to subtract by the number of the middle walls. In other symbol, it can be written as follows: $\mathrm{F} 1 \rightarrow 6, \mathrm{~F} 2 \rightarrow 2 \times 6-1, \mathrm{~F} 3 \rightarrow 3 \times 6-2 \ldots$ So, on Fig 10 the number of matchsticks is $10 \times 6-9=51$, therefore on Fig 30 the number of matchsticks is $30 \times 6-29=151$.

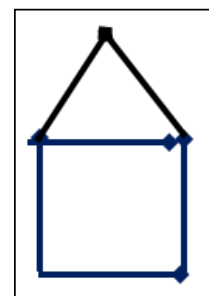

Fig 1

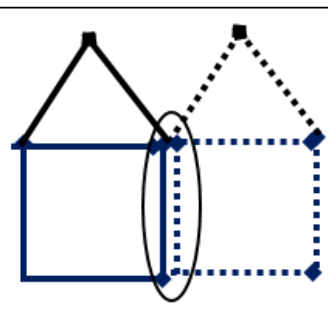

Fig 2

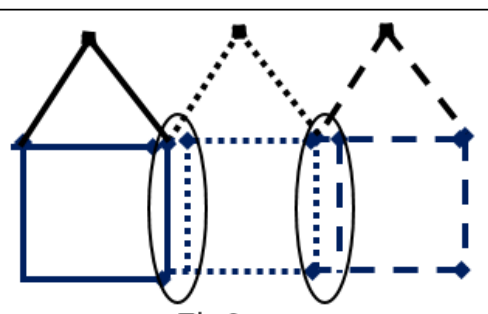

Fig 3

Figure 8. Alternative 8 in finding the number of matchstick on Fig 30

\section{Alternative 9}

By using ELPS and the alternative shown in Figure 8, students can discover that each house consist of 2 matchsticks on the roof of each house of each figure. The number of matchstick on each house is 4 , however the middle walls of the house has been counted twice, so the students have to subtract by the number of the middle walls. In other symbol, students can learn that: $\mathrm{F} 1 \rightarrow 2+4, \mathrm{~F} 2 \rightarrow 2 \times 2+2 \times 4-1, \mathrm{~F} 3 \rightarrow 3 \times 2+3 \times 4-2 \ldots$ So, on Fig 10 the number of 
matchsticks is $10.2+10.4-9=51$, while on Fig 30 the number of matchsticks is $30.2+30.4-29$ $=151$.

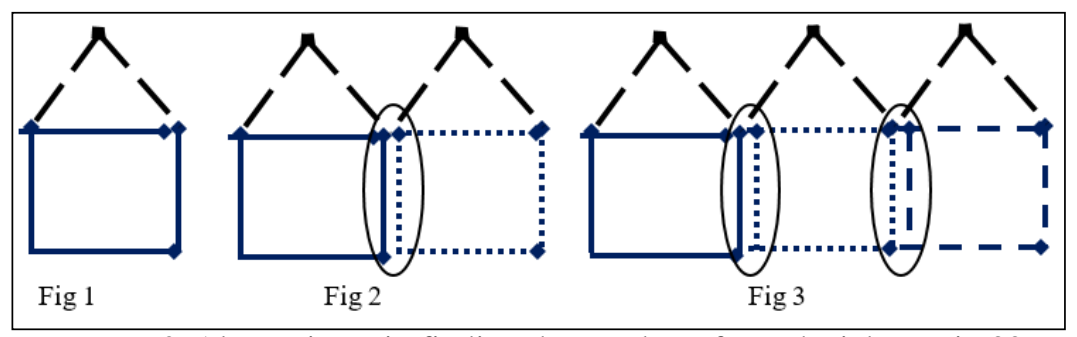

Figure 9. Alternative 9 in finding the number of matchstick on Fig 30

\section{Alternative 10}

By using ELPS and the diagram below students can discover that each house consist of 2 matchsticks on the roof each house, 2 matchsticks on the two horizontal line, and the number of house plus one matchsticks is needed as represented by the vertical line. In other symbol, students can learn that: $\mathrm{F} 1 \rightarrow 2+2+1+1, \mathrm{~F} 2 \rightarrow 2 \times 2+2 \times 2+2+1, \mathrm{~F} 3 \rightarrow 3 \times 2+3 \times 2+3+1 \ldots$ The number of matchsticks to build Fig 10 is $10 \times 2+10 \times 2+10+1=51$, while to make Fig 30 the number of matchsticks needed is $30 \times 2+30 \times 2+30+1=151$.

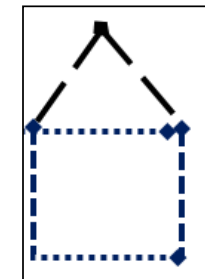

Fig 1

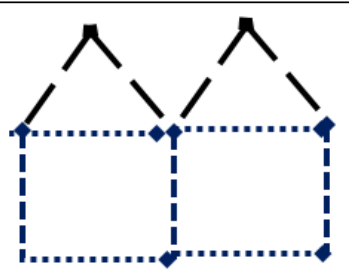

Fig 2

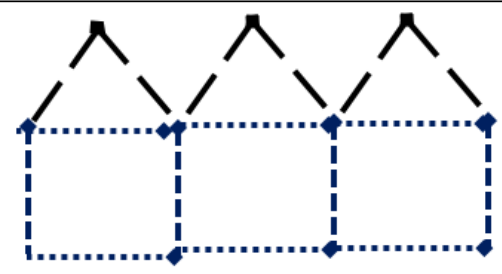

Fig 3

Figure 10. Alternative 10 in finding the number of matchstick on Fig 30

\section{Alternative 11}

The last alternative shows that each house consist of 3 matchsticks on the roof and ceiling of each house, 1 matchstick on the ground floor of each house, and the number of house plus 1 matchstick as represented by the vertical lines. F1 $\rightarrow 3+1+1+1, \mathrm{~F} 2 \rightarrow 2 \times 3+2 \times 1+2+1, \mathrm{~F} 3 \rightarrow$ $3 \times 3+3 \times 1+3+1 \ldots$ So, on Fig 10 the number of matchsticks is $10 \times 3+10 \times 1+10+1=51$, while on Fig 30 the number of matchsticks is $30 \times 3+30 \times 1+30+1=151$.

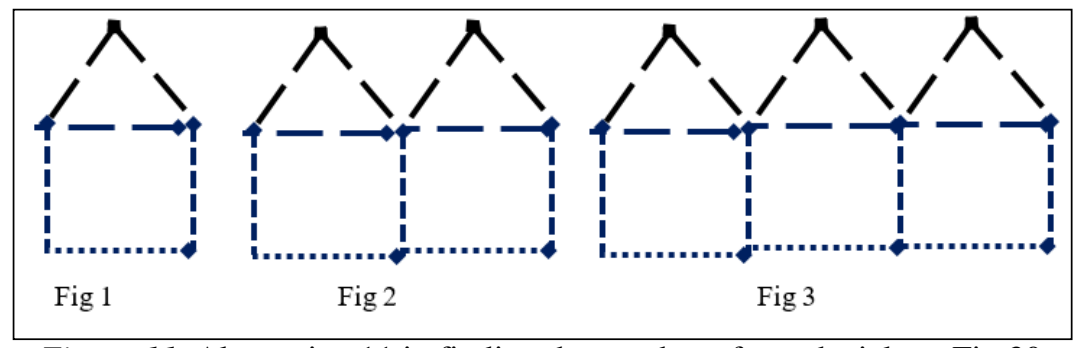

Figure 11. Alternative 11 in finding the number of matchstick on Fig 30 


\section{Conclusion}

The example of lesson above which is started with a problem as proposed by Isoda and then apply Lowrie and Patahuddin (2015) framework in the teaching and learning of mathematics encourages students to learn mathematics meaningfully and joyfully, help them to think and to be independent learners. In addition, a lesson that is started with a problem from Lowrie and Patahuddin (2015) can be used and applied to help learners to enhance their attitudes and values through experiencing: (1) the beauty of mathematics, (2) the curiosity to learn mathematics, (3) the reasonableness of mathematics results, and (4) good or positive appreciation of the teaching and learning of mathematics, as proposed by Isoda (2015a). Also, a lesson that is started with problem from Lowrie and Patahuddin (2015) could be used and applied to help learners to enhance the Indonesian SA. It can be concluded that the teaching and learning of mathematics should be started with problems (contextual, realistic or mathematics) to ensure that our students can be facilitated to learn to think and to reason.

In solving the problem from Lowrie and Patahuddin (2015), the second step on PSA, proposed by Isoda (2015a), that is 'independent solving' can be elaborated by using ELPSA (Lowrie \& Patahuddin, 2015) or Indonesian SA. It cannot be denied, concerning the importance of the first step of PSA, that 'problem posing' could help learners to think and to be independent learners. In addition, the importance of all aspects of ELPSA and all steps of Indonesian SA can be executed by Indonesian students.

\section{Recommendations}

In an improved classroom the three frameworks show that the teaching learning process should be started contextually. Every mathematics teacher should be encouraged and motivated to produce such high quality teaching and learning resource materials including the designing of a lesson plan that starts with activities or contextual/realistic/mathematical problems, hypothetical learning trajectory.

LS gets mathematics teachers to Plan $\rightarrow$ Do $\rightarrow$ See and teachers need to experience mathematics in ways that they will be expected to teach (Darling-Hammond, 2000). Mathematics teachers need concrete examples and experiences as soon as possible and ideally when they are sitting in pre-service institutions they will be ready to facilitate their students in mathematics classes. Teachers are more likely to implement the new approaches in their own classes if they have experienced it in their own learning experiences. SEAQiM offers courses that provide teachers with rich experiences of teaching strategies.

In Japan, the LS activity is supported by university experts. Every pre-service and inservice institution has to work with and help elementary and secondary school teachers. If we learn from Japan then every pre-service and in-service institution could focus on helping and 
facilitating learners. The main focus of pre-service institutions should be on producing mathematics teachers who can help their students to learn mathematics meaningfully, to think logically and creatively, and to be independent learners.

Further research should be designed to examine and challenge Indonesian mathematics teachers' beliefs which have an impact on their classroom practice, on the ways they perceive teaching, learning, and assessment, and on the ways they perceive students' potential, abilities, dispositions, and capabilities. This knowledge could be used to change their beliefs.

\section{References}

Askew, M. (2013). Launching futures: You can't drive by looking in the rearview mirror. In S. Herbert, J. Tillyer, \& T. Spencer (Eds.), Proceedings of the $24^{\text {th }}$ Biennial Conference of the Australian Association of Mathematics Teachers (pp. 4-13). Adelaide: The Australian Association of Mathematics Teachers (AAMT) Inc.

De Lange, J. (2004). Mathematical literacy for living from OECD-PISA perspective. Paris: OECD-PISA.

Darling-Hammond, L. (2000). Teacher quality and student achievement. Education Policy Analysis Archives, 14(1), 162-183.

Fitzgerald, M., \& James, I. (2007). The mind of the mathematician. Baltimore: The Johns Hopkins University Press.

Goos, M., Stillman, G., \& Vale, C. (2007). Teaching secondary school mathematics:

Research and practice for the $21^{\text {st }}$ century. NSW: Allen \& Unwin

Isoda, M., \& Katagiri, S. (2012). Mathematical thinking. Singapore: World Scientific.

Kemendikbud (2014). Gawat darurat pendidikan di Indonesia. Power Point presented by the Minister of Education and Culture of the Republic of Indonesia in front of the Head of Education and Culture Districts Offices. Jakarta: Kemendikbud.

Lowrie, T., \& Patahuddin, S. M. (2015). ELPSA - Kerangka Kerjauntuk Merancang Pembelajaran Matematika. Jurnal Didaktik Matematika, 2(1), 94-108.

MoEC (2014). Implementasi kurikulum 2013. Jakarta: Kemdikbud.

National Council for Teachers of Mathematics (NCTM) (2000). Principles and standards for school mathematics. Reston VA: author

National Research Council (NRC) (1989). Everybody counts. A Report to the nation on the future of mathematics education. Washington DC: National Academy Press.

SEAMEO RECSAM (2016). Working paper for SEA-BES: Common core regional learning standards in science and mathematics. Penang: SEAMEO RECSAM.

SEAMEO RECSAM (2015). SEA-BES: Common core regional learning standards in mathematics framework for the $21^{\text {st }}$ century. Retrieved from 
https://fadjarp3g.wordpress.com /2016/07/27/standards-for-mathematics-and-scienceteacher-and-standards-on-basic-education-for-mathematics-and-science/

Shadiq, F. (2010). Identifikasi kesulitan guru matematika SMK pada pembelajaran matematika yang mengacu pada permendiknas No. 22 Tahun 2006. Edumat: Jurnal Edukasi Matematika, 1(1), 49-60.

Shadiq, F. (2015). How can SEAMEO QITEP in Mathematics helps Indonesian mathematics teachers to help their students to be independent learners in the case of disaster risk reduction (DRR)? Paper presented on Conference on Science and Mathematics Education (CoSMEd), SEAMEO RECSAM, Penang, Malaysia, 16-19 November, 2015. Yogyakarta: SEAMEO QITEP in Mathematics.

Shadiq, F. (2016a). The opportunities and challenges on the teaching and learning of mathematics: Experience of SEAMEO QITEP in Mathematics. Power Point Presented on the Workshop on Promoting Mathematics Engagement and Learning Opportunities for Disadvantaged Communities in West Nusa Tenggara in Australian Embassy, Jakarta, 12 May, 2016. Yogyakarta: SEAMEO QITEP in Mathematics.

Shadiq, F. (2016b). The Japanese problem solving approach (PSA). Power Point Presented on Course on Joyful Learning for Primary School Teachers. SEAMEO QITEP in Mathematics, Yogyakarta, 24 August-6 September 2016. Yogyakarta: SEAMEO QITEP in Mathematics.

White, A. L. (2014). Recipes for success: Essential ingredients for good mathematics teachers and teaching. In A. L. White, S. Tahir, \& U. H. Cheah, (Eds.), Empowering future generations through mathematics education (pp. 142-160). Penang Malaysia:

SEAMEO RECSAM. 